Egyptian Journal for Aquaculture

ISSN: 2090-7877

www.braesd.org

Khater et al., 2018; 8(3):13-32

\title{
Techno-Financial Study for Some Sex Reversal Methods of Nile Tilapia Fish
}

\author{
Khater E. G. *, S. A. Ali*, W. E. Mohamed ** and T. I. Dawood** \\ *Agricultural Engineering Department, Faculty of Agriculture, Benha \\ University, Egypt \\ **Central Laboratory for Aquaculture Research, Abbassa, Abou-Hammad, \\ Sharkia, Egypt \\ Received: March 10, 2018; Accepted: July 29, 2018 Vol.8 (3):13-33
}

\begin{abstract}
The main aim of this work is a techno-financial evaluation for some sex reversal methods of Nile tilapia. To achieve that study the effect of water temperatures $\left(25,30\right.$ and $\left.35{ }^{\circ} \mathrm{C}\right)$, hormone levels (without (0) and $60 \mathrm{mg} 17 \alpha-\mathrm{MT} / \mathrm{kg}$ feed) and periods of time (1, 2, 3 and 4 weeks) on the male ratio, mortality rate, weight gain of Nile tilapia fries, energy consumption and costs of heating water and hormone were assessed. The obtained results indicated that the male ratio and mortality rate increased with the increasing of water temperature, hormone doses and rearing period. The highest value of weight gain $(2.56 \mathrm{~g})$ was obtained at $30{ }^{\circ} \mathrm{C}$ water temperature with $60 \mathrm{mg} 17 \alpha-\mathrm{MT} / \mathrm{kg}$ feed after four weeks of rearing. The energy consumption for heating water increased with the increase of water temperature and rearing period. The costs of heating water and hormone increased with increasing water temperature, hormone doses and rearing period. The water temperature of $35^{\circ} \mathrm{C}$ with $60 \mathrm{mg} 17 \alpha-\mathrm{MT} /$ $\mathrm{kg}$ feed after two weeks gave the best results of male ratio and costs compared to water temperature of $35^{\circ} \mathrm{C}$ with 0 hormone doses after four weeks. In addition, the water temperature of $35^{\circ} \mathrm{C}$ with $60 \mathrm{mg} 17 \alpha-\mathrm{MT} / \mathrm{kg}$ feed after one week gave the best results of male ratio and costs compared to water temperature of $35^{\circ} \mathrm{C}$ with 0 hormone doses after three weeks.
\end{abstract}

Keywords: Nile tilapia - temperature - Male ratio - Sex ratio - Weight gain - Specific growth rate - Feed conversion ratio 


\section{INTRODUCTION}

Tilapia is the generic name of a large range of fish species of cichlids. The original distribution of this group was south-central Africa northward into Syria, where more than 70 species have been identified (Popma and Phelps, 1998). Tsadik and Bart (2007) reported that Nile tilapia, Oreochromis niloticus (Linnaeus, 1758) is the main genus Oreochromis with potential for aquaculture due to its rusticity and rapid growth, reaching commercial weight in small interval of time; great capacity for adaptation to confinement and the various systems of farming, high capacity for hybridization, which allows the characters unit desired; tolerance to wide variations in salinity, temperature and concentrations of dissolved oxygen, high resistance to diseases, high quality meat with its clear color, and high acceptance by the consumer (Tsadik and Bart, 2007).

Tilapia males have a higher weight gain and better-feed conversion when compared with females under same conditions. Males grow 1825\% faster than females (Macintosh and Little, 1995 and SotoZarazúa et al., 2011). There are various techniques of sex reversal, or more specifically the production of masculinization monosex culture. Among the techniques used for sex reversal in tilapia, the most widespread in the world is the use of hormone incorporated in the diet, especially the 17 -methyltestosterone (Guerrero III and Guerrero, 1997).

Monosex males may be obtained by (1) manual sorting of fingerlings based on anatomy is extremely laborious and does not have high resolution, (2) hybridization, (3) hormonal sex reversal used to produce larger numbers and (4) water temperature (Tessema et al., 2006).

Production of mono-sex populations in several fish species require sex reversal, which is induced by steroid hormones (Shelton et al., 1995). Of these androgens and oestrogens are used as masculinizing and feminizing agents, respectively. These steroid hormones are commonly applied by oral or immersion treatments. Oral administration of the synthetic androgen $17 \alpha$-methyltestosterone (MT) has been effective in producing all male populations in carps. All male population increases the efficiency and feasibility of carp aquaculture. There have been numerous published attempts to optimize the methods of sex reversal by varying 
parameters such as hormone dose, treatment start time, duration of treatment and stocking density (Mubarik et al., 2011).

Khater (1999) indicated that the male ratio found to be $67.25,91.87$ and $95.68 \%$ for the duration treatment period of 14, 21 and 28 days, respectively, when Nile tilapia fry fed diet containing $60 \mathrm{mg}$ of $17 \alpha-$ $\mathrm{MT} / \mathrm{kg}$ feed.

Celik et al. (2011) tried to produce all male Nile tilapia by feeding its larvae with diet containing $17 \alpha-\mathrm{MT}$ at five different doses $(0,20,30,40$, 50 and $60 \mathrm{mg} / \mathrm{kg}$ feed) for 28 days. Since the androgens have both sex reversal and anabolic effects. The same authors also stated that, the sex reversed tilapia shows a better growth performance as compared to normal tilapia.

Temperature is one of the most commonly studied environmental factors that influence sexual determination in fish (Devlin and Nagahama, 2002). The phenotypic sex in Nile tilapia is a complex trait, it is determined through interplay between major genetic and minor genetic factors and temperature. The response of the phenotypic sex to thermal treatments $\left(>34{ }^{\circ} \mathrm{C}\right)$ during a 10-day period after yolk sac absorption is proven to be under genetic control (Baroiller et al., 1996). Former experiments using elevated temperatures $\left(36{ }^{\circ} \mathrm{C}\right.$ for ten days) in Nile tilapia fry, Tessema et al. (2006) showed that, differences of thermal responsiveness exist within and between Nile tilapia populations. The same authors also stated that, further increase in males was not obtained with the $38^{\circ} \mathrm{C}$ treatment in most of the tested progenies in both populations. Nonetheless, the low temperature treatment $\left(18^{\circ} \mathrm{C}\right)$ was, in general, not effective in influencing the sex ratios. In the Lake Manzala population, $66 \%$ of the temperature-treated progenies $\left(36^{\circ} \mathrm{C}\right)$ showed sex ratios with more than $80 \%$ males, while in the Lake Rudolph population, no temperature-treated progeny $\left(36^{\circ} \mathrm{C}\right)$ showed such a corresponding surplus of males (Wessels and Hörstgen-Schwark, 2007). They mentioned that, a selection experiment revealed that selection for the male proportion in the temperature treated groups can be successful. The same authors also showed that, after two generations of divergent selection for the male proportion in temperature treated groups, male percentages of $90 \%$ and $54 \%$ were obtained in the high- and low-line, respectively. 
Due to the harmful effect of the hormone used to produce monosex fish on human health due to its accumulation in fish body and it should careful to use it in order to produce monosex fish and therefore, the main aim of this work is to techno-financial evaluation for some sex reversal methods of Nile tilapia fish.

\section{MATERIALS AND METHODS}

The experiment was carried out at Agricultural and Bio-Systems Engineering Department, Faculty of Agriculture, Moshtohor, Benha University, Egypt. During the period of February to April 2018.

\section{Materials:}

\section{System description:}

The experiment was conducted in the laboratory. Seventy-two glass tanks were used for tilapia fry culture; dimensions of each tank are $50 \mathrm{~cm}$ long, $25 \mathrm{~cm}$ wide and $30 \mathrm{~cm}$ high. The water volume used in each tank was 30 liters stored with 300 new hatched tilapia fry (four days old and $0.025 \mathrm{~g}$ weight). Each tank equipped with $15 \mathrm{~W}$ air blower of flow rate $850 \mathrm{~L} \mathrm{~h}^{-1}$ at $1.5 \mathrm{~m}$ head to increase dissolved oxygen concentrations.

The effluent water of the glass rearing tanks was passing through the filter unit, after that water passes through heater before it was returned to the fish tank by pump. The use of new water by the system was low. Daily partial water was added per day to reduce the accumulation of excreted ammonia and substitute the water losses due to the evaporation. Each tank equipped with $150 \mathrm{~W}$ heater and thermostat to maintain the predetermined temperatures $\left(25,30\right.$ and $\left.35^{\circ} \mathrm{C}\right)$.

The hormone treated feed was prepared as described by (Killian and Kohler, 1991). The $17 \alpha$-methyl testosterone (MT) used in the present study was obtained from the (Sigma Chemical Ltd.). A stock solution was made by dissolving $1 \mathrm{~g}$ of hormone in $1 \mathrm{~L}$ of $95 \%$ ethanol. Treatments were made by taking the accurate amount of the hormone from stock solution and brought up to $100 \mathrm{ml}$ by addition $95 \%$ ethanol. This solution was evenly sprayed over $1 \mathrm{~kg}$ of the diet and diet and mixed. The mixture was mixed again and this was repeated to ensure an equal distribution of the MT throughout the feed. Treated diets were fan dried in shade at $25^{\circ} \mathrm{C}$ for 24 hours then kept in freezer until use.

During the experimental period, continuous monitoring and recoding of the main water quality parameters took place. Dissolved oxygen and temperature were measured by using the dissolved oxygen meter, 
provided with a dissolved oxygen probe (No. 81010). Total ammonia nitrogen (TAN) was measured by ion selective electrode (ORION 710). The fish weight was measured by electric digital balance (Model HG 5000 - Range 0 - $5000 \mathrm{~g} \pm 0.01 \mathrm{~g}$, Japan).

\section{Methods:}

Nile Tilapia fries, which were used in the experiment, were conveyed from hatchery unit of the World Fish Center (WFC), Abbassa, AbouHammad Sharkia, Egypt. The daily feed rates at different fish sizes were applied according to the recommendations of Rakocy (1989) and the feed pellet diameter was prepared according to Jauncey and Ross (1982). Feeding was stopped during weighing process.

\section{Experimental design:}

The treatments were arranged in a split split plot design in three replications. Three water temperatures are 25,30 and $35{ }^{\circ} \mathrm{C}$ and two levels hormone ( 0 and $60 \mathrm{mg} 17 \alpha-\mathrm{MT} / \mathrm{kg}$ feed). Four periods of time are 1, 2, 3 and 4 weeks.

All treatments tanks were placed in a lab where a water recycling unit used to supply the tank with temperature controlled water.

\section{Measurements:}

After each mentioned period of time for each treatment, a sample of 100 fry was collected from each tank to undergo sex ratio check using the Squash Technique (Guerrero and Shelton, 1974). Fish samples were killed by cold shock (water temperature of $0^{\circ} \mathrm{C}$ ), weighed, measured and dissected. Fish sample were taken to determine the weight gained of the fish as following:

$$
W G=W_{f}-W_{i}
$$

Where:

WG is the weight gained, $\mathrm{g}$

$\mathrm{W}_{\mathrm{f}}$ is the mean final fish weight, $\mathrm{g}$

$\mathrm{W}_{\mathrm{i}}$ is the mean initial fish weight, $\mathrm{g}$

\section{Theoretical Approach}

Figure (1) represents the energy balance described by the following mathematical expression: 


$$
(\mathrm{dq} / \mathrm{dt})= \pm \mathrm{q}_{\mathrm{rad}} \pm \mathrm{q}_{\mathrm{conv}} \pm \mathrm{q}_{\mathrm{cond}}-\mathrm{q}_{\mathrm{evap}}+\mathrm{q}_{\mathrm{in}}-\mathrm{q}_{\mathrm{drain}} \pm \mathrm{q}_{\text {other }}
$$

Where:-

$\mathrm{q}$ is the total energy $(\mathrm{kJ})$ at any given time $(\mathrm{t})$ in the pond per $\mathrm{m}^{2}$

qrad is the rate of heat exchange by radiation, $\mathrm{kW} \mathrm{m}^{-2}$

$\mathrm{q}_{\mathrm{conv}}$ is the rate of heat exchange with the air by convection, $\mathrm{kW} \mathrm{m}^{-2}$

$\mathrm{q}_{\mathrm{cond}}$ is the rate of heat exchange with the wall, $\mathrm{kW} \mathrm{m}^{-2}$

$\mathrm{q}_{\text {evap }}$ is the rate of heat lost through the evaporation of water, $\mathrm{kW} \mathrm{m}^{-2}$

$\mathrm{q}_{\text {in }}$ is the rate of bulk energy gain from makeup water, $\mathrm{kW} \mathrm{m}^{-2}$

$\mathrm{q}_{\mathrm{drain}}$ is the rate of bulk energy lost to the overflow of water, $\mathrm{kW} \mathrm{m}^{-2}$

$\mathrm{q}_{\text {other }}$ is the rate of energy transfer from or to other sources, $\mathrm{kW} \mathrm{m}^{-2}$

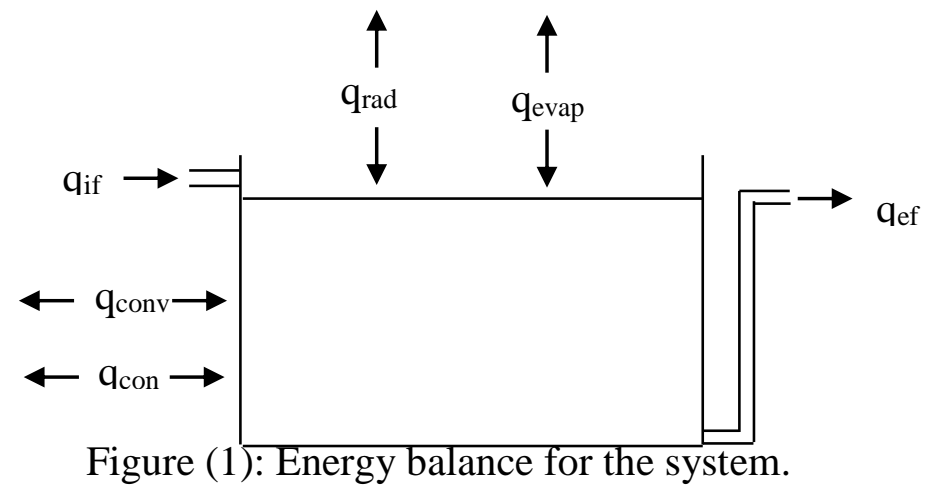

The rate of heat exchange due to pond radiation is:

$$
q_{\text {rad }}=0.97 e \sigma\left(T_{\text {air }}\right)^{4}
$$

Where:-

$\mathrm{q}_{\mathrm{rad}}$ is the heat exchange due to pond radiation $\left(\mathrm{kW} \mathrm{m}^{-2}\right)$

$\sigma$ is the Stefen-Boltzmann constant $\left(5.67 \times 10^{-11} \mathrm{~kW} \mathrm{~m}^{-2} \mathrm{~K}^{-4}\right)$

$\mathrm{T}_{\text {air }}$ is absolute air temperature $2 \mathrm{~m}$ above the water surface $(\mathrm{K})$

$\mathrm{e}$ is average emittance of the atmosphere (dimensionless)

The average emittance of the atmosphere terms can be calculated according to the following equations (Bliss, 1961):

$$
e=0.398 \times 10^{-5}\left(T_{\text {air }}\right)^{2.148}
$$

The conduction of heat between the inner surface and the outer surface was calculated as: 


$$
q_{\text {cond }}=k\left(T_{i}-T_{o}\right) / z
$$

Where:-

$\mathrm{q}_{\mathrm{cond}}$ is the rate of heat transfer through conduction $\left(\mathrm{kW} \mathrm{m}^{-2}\right)$

$\mathrm{k}$ is thermal conductivity coefficient $\left(\mathrm{kW} \mathrm{m} \mathrm{m}^{-1} \mathrm{~K}^{-1}\right)$

$\mathrm{T}_{\mathrm{i}}$ is temperature of the inner surface $(\mathrm{K})$

$\mathrm{T}_{\mathrm{o}}$ is temperature of the outer surface $(\mathrm{K})$

$\mathrm{Z}$ is thickness of material $(\mathrm{m})$

For system, conduction occurs in two places, the bottom and the walls of pond.

Heat transferred through convection can be calculated using Newton's Law of cooling:

$$
q_{\text {conv }}=h\left(T_{\text {surface }}-T_{\text {fluid }}\right)
$$

Where

$\mathrm{q}_{\mathrm{conv}}$ is the heat transferred by convection $\left(\mathrm{kW} \mathrm{m}^{-2}\right)$

$\mathrm{h}$ is the heat transfer coefficient $\left(\mathrm{kW} \mathrm{m}^{-2} \mathrm{~K}^{-1}\right)$

$\mathrm{T}_{\text {surface }}$ is the temperature of the surface $(\mathrm{K})$

$\mathrm{T}_{\text {fluid }}$ is the temperature of the cooling (or heating) fluid (K).

For system, convection occurs in two places, the wall-water interface and the water-air interface.

Nusselt number $(\mathrm{Nu})$ correlations are traditionally used to predict a heat transfer coefficient, depending on:

- The geometry of the surface

- The properties of the cooling fluid

- The velocity at which the cooling fluid is moving

The Nusselt number, a dimensionless number, is the ratio between the rate of convection to the rate of conduction in a fluid. Numerically, the Nusselt number $(\mathrm{Nu})$ is related to the heat transfer coefficient by:

$$
N_{u}=\frac{h L_{c}}{k_{\text {air }}}
$$

Where

$\mathrm{L}_{\mathrm{c}}$ is the characteristic length of the surface $(\mathrm{m})$

$\mathrm{h}$ is the heat transfer coefficient $\left(\mathrm{kW} \mathrm{m}^{-2} \mathrm{~K}^{-1}\right)$ 
$\mathrm{k}_{\text {air }}$ is the thermal conductivity of the air $\left(\mathrm{kW} \mathrm{m}^{-1} \mathrm{~K}^{-1}\right)$

$$
\begin{gathered}
k_{\text {air }}=\left(1.52 E-11 x T_{\text {air }}^{3}-4.86 E-08 x T_{\text {air }}^{2}+1.02 E-04 x T_{\text {air }}-3.93 E-04\right) / 1000 \\
L_{c}=\frac{\text { Area }}{\text { Perimeter }}
\end{gathered}
$$

The Rayleigh number is:

$$
R_{a}=\frac{g \beta\left(T_{\text {water }}-T_{\text {air }}\right) L_{c}^{3}}{v_{\text {air }}^{2}}
$$

Where

$\mathrm{g}$ is the gravitational acceleration $\left(9.81 \mathrm{~m} \mathrm{~s}^{-2}\right)$

$\beta$ is the coefficient of thermal expansion $\left(\mathrm{K}^{-1}\right)$

$\mathrm{T}_{\text {water }}$ is the temperature of water $(\mathrm{K})$

$V_{\text {air }}$ is the kinematic viscosity of the air $\left(\mathrm{m}^{2} \mathrm{~s}^{-1}\right)$

Estimates for the case of a flat horizontal plate where the plate (in this case, the water) is warmer than the cooling fluid (in this case, the air), the following empirical correlations apply (Holman, 1997):

$$
\begin{aligned}
& \mathrm{Nu}=0.54 \mathrm{Ra}^{0.25} \quad \text { if } \mathrm{Ra} \text { is between } 10^{4} \text { and } 10^{7} \text {. } \\
& \mathrm{Nu}=0.15 \mathrm{Ra}^{1 / 3} \quad \text { if } \mathrm{Ra} \text { is between } 10^{7} \text { and } 10^{11}
\end{aligned}
$$

If the plate is cooler than the fluid, and $\mathrm{Ra}$ is between $10^{5}$ and $10^{10}$, then

$$
\mathrm{Nu}=0.54 \mathrm{Ra}^{1 / 4}
$$

The rate of bulk energy moved across the system boundary can calculated with the following equation:

$$
q=\dot{m} C p T_{\text {water }}
$$

Where

$\dot{m}$ is the mass flow rate of water into (or out of) the system,

$\mathrm{Cp}$ is the specific heat of water and

$\mathrm{T}_{\text {water }}$ is the temperature of the water.

The process of evaporation requires a lot of energy. Evaporation heat losses ( $\mathrm{q}_{\text {evap}}$ ) are calculated with the following set of equations (Anonymous, 1992): 


$$
q_{\text {evap }}=\frac{m_{\text {evap }}^{\bullet} h_{f g}}{A}=\frac{Q_{e} \rho_{w} h_{f g}}{A}
$$

Where

$m_{\text {evap }}^{\bullet}$ is the rate of evaporation $\left(\mathrm{kg} \mathrm{s}^{-1}\right)$

$\mathrm{h}_{\mathrm{fg}}$ is the latent heat of vaporization $\left(\mathrm{kJ} \mathrm{kg}^{-1}\right)$

A is the surface area of the pond $\left(\mathrm{m}^{2}\right)$

$\mathrm{Q}_{\mathrm{e}}$ is the water lost to evaporation $\left(\mathrm{m}^{3} \mathrm{~s}^{-1}\right)$

Alternately, the following equation can used to estimate the rate of evaporation (Piedrahita, 1991):

$$
Q_{e}=2.241 \times 10^{-3} x V_{2} x\left(e_{s}-e_{a}\right)
$$

Where

$\mathrm{Q}_{\mathrm{e}}$ is the rate of evaporation $\left(\mathrm{m}^{3} \mathrm{~s}^{-1}\right)$

$\mathrm{V}_{2}$ is the wind velocity 2 meters above the pond surface $\left(\mathrm{m} \mathrm{s}^{-1}\right)$ (Khater, 2012)

$\mathrm{e}_{\mathrm{s}}$ is the saturated vapor pressure $(\mathrm{Pa})$

$\mathrm{e}_{\mathrm{a}}$ is the air vapor pressure $(\mathrm{Pa})$

$$
\begin{aligned}
& e_{s}=25.374 x \operatorname{Exp}\left(17.62-\frac{5271}{T_{\text {water }}}\right) \times\left(\frac{760 m m H g}{101300 P a}\right) \\
& e_{a}=R H x 25.374 x \operatorname{Exp}\left(17.62-\frac{5271}{T_{\text {air }}}\right) \times\left(\frac{760 m m H g}{101300 P a}\right)
\end{aligned}
$$

Where

$\mathrm{RH}$ is the Relative Humidity (\%)

All computational procedures of the model were carried out using Excel spreadsheet. The computer program was devoted to energy balance for predicting the energy requirement for heating water.

\section{Costs analysis}

Calculation the costs for heating water to maintain the water temperature requirement and compared to costs of hormone. 


\section{Statistical analysis}

The statistical analysis for the data obtained was done according to Snedecor and Cochran (1980) and the treatments were compared using Least Significant Differences (LSD) test at 99\% confidence level (Gomez, 1984).

\section{RESULTS AND DISCUSSIONS}

\section{Male ratio:}

Table (1) shows the male ratio of Nile tilapia under the two levels of hormone dose ( 0 and $60 \mathrm{mg} 17 \alpha-\mathrm{MT} / \mathrm{kg}$ feed) as affected by water temperatures; 25, 30 and $35{ }^{\circ} \mathrm{C}$ and time periods from 1 to 4 weeks. Regarding of the effect water temperature, could be seen that the average values of the male ratio were $66.27,83.08$ and $89.04 \%$ for Nile tilapia fries rearing at 25,30 and $35{ }^{\circ} \mathrm{C}$ water temperature, respectively depending on the period and hormone level. The results revealed that the male ratio of Nile tilapia increased with increasing the water temperature from 25 to $35{ }^{\circ} \mathrm{C}$. Rearing at $35{ }^{\circ} \mathrm{C}$ water temperature gave the best results of male ratio for all period of time rearing and level of hormone with significant differences. These results were in agreement with those obtained by Tessema et al., (2006) who is found that, the high water temperature $\left(36^{\circ} \mathrm{C}\right)$ increased the male ratio more than $80 \%$. Nonetheless, Bezault et al., (2007) found that, the high water temperature increased the male ratio to $91.2 \%$ at water temperature $36^{\circ} \mathrm{C}$.

Table (1): Effect of water temperature, period and level of hormone on male ratio of Nile tilapia.

\begin{tabular}{|c|c|c|c|c|c|c|c|}
\hline \multirow{3}{*}{$\begin{array}{c}\text { Hormone } \\
\text { Dose, } \mathrm{mg} \\
\mathrm{kg}^{-1}\end{array}$} & \multirow{3}{*}{$\begin{array}{c}\text { Water } \\
\text { Temperature, } \\
{ }^{\circ} \mathrm{C} \\
\end{array}$} & \multicolumn{5}{|c|}{ Time Period, week } & \multirow{3}{*}{ Mean } \\
\hline & & 1 & 2 & 3 & & 4 & \\
\hline & & \multicolumn{5}{|c|}{ Mate Ratio, \% } & \\
\hline \multirow{4}{*}{0} & 25 & $50.86^{\mathrm{a}}$ & $56.44^{\mathrm{b}}$ & \multicolumn{2}{|c|}{$64.04^{\mathrm{d}}$} & $68.28^{\mathrm{g}}$ & $59.91^{\mathrm{a}}$ \\
\hline & 30 & $65.41^{\mathrm{e}}$ & $73.92^{\mathrm{h}}$ & \multicolumn{2}{|c|}{$81.63^{1}$} & $84.35^{\mathrm{k}}$ & $76.33^{\mathrm{c}}$ \\
\hline & 35 & $73.00^{\mathrm{h}}$ & $83.18^{\mathrm{k}}$ & \multicolumn{2}{|c|}{$87.78^{1}$} & $90.65^{\mathrm{m}}$ & $\mathbf{8 3 . 6 5}^{\mathrm{d}}$ \\
\hline & Mean & $63.09^{a}$ & $71.18^{b}$ & \multicolumn{2}{|c|}{$77.82^{d}$} & $81.09^{\mathrm{e}}$ & \\
\hline \multirow{4}{*}{60} & 25 & $57.68^{\mathrm{c}}$ & $66.82^{\mathrm{f}}$ & \multicolumn{2}{|c|}{$79.78^{\mathrm{g}}$} & $86.19^{\mathrm{m}}$ & $72.62^{b}$ \\
\hline & 30 & $76.91^{\mathrm{i}}$ & $90.98^{\mathrm{n}}$ & \multicolumn{2}{|c|}{$94.26^{\circ}$} & $97.03^{p}$ & $\mathbf{8 9 . 8 0}^{\mathrm{e}}$ \\
\hline & 35 & $86.95^{\mathrm{m}}$ & $94.86^{\circ}$ & \multicolumn{2}{|c|}{$96.90^{\mathrm{p}}$} & $98.98^{\mathrm{q}}$ & $94.42^{\mathrm{f}}$ \\
\hline & Mean & $73.85^{\mathrm{c}}$ & $84.22^{\mathrm{f}}$ & \multicolumn{2}{|c|}{$90.31^{\mathrm{g}}$} & $94.07^{\mathrm{h}}$ & \\
\hline \multirow{2}{*}{$\mathrm{LSD}_{0.05}$} & $\mathrm{~A}$ & $\mathrm{~B}$ & $\mathrm{C}$ & $\mathrm{AB}$ & $\mathrm{AC}$ & $\mathrm{BC}$ & $\mathrm{ABC}$ \\
\hline & 0.276 & 0.338 & 0.478 & 0.390 & \multicolumn{2}{|c|}{\begin{tabular}{l|l}
25 & 0.676 \\
\end{tabular}} & 0.956 \\
\hline
\end{tabular}


Concerning the effect of period of rearing, the results indicate that the male ratio of Nile tilapia increases with increasing period of rearing. It could be seen that the average values of male ratio were significantly increased from 68.47 to $87.04 \%$, when the period increasing from 1 to 4 weeks depending on the water temperature and hormone level. These results agreed with those obtained by Khater (1999) and Khater $\boldsymbol{e t}$ al., (2017) in which the male ratio of Nile tilapia enhanced by period during rearing. The results also indicate that the male ratio of Nile tilapia ranged from 73.30 and $85.61 \%$ for 0 and $60 \mathrm{mg} 17 \alpha-\mathrm{MT} / \mathrm{kg}$ feed, respectively. These results agreed with those obtained by Celik $\boldsymbol{e t}$ al., (2011). The statistical analysis showed that the differences between the obtained data of male ratio of Nile tilapia due to the effect of water temperature (A), time period (B) and level of hormone (C) were significant. The analysis showed also that the interaction between both $\mathrm{AB}, \mathrm{AC}, \mathrm{BC}$ and $\mathrm{ABC}$ were significant.

\section{Mortality rate:}

Table (2) shows the mortality rate of Nile tilapia under two levels of hormone dose ( 0 and $60 \mathrm{mg} 17 \alpha-\mathrm{MT} / \mathrm{kg}$ feed) as affected by water temperatures from 25 to $35{ }^{\circ} \mathrm{C}$ and time periods from 1 to 4 weeks. Regarding of the effect water temperature, the results indicate that the mortality rate increases with increasing water temperature. It could see that the average values of the mortality rate significantly increased from 12.08 to $16.23 \%$, when the water temperature increased from 25 to 35 ${ }^{\circ} \mathrm{C}$ depending on the period and hormone level. Rearing at $25{ }^{\circ} \mathrm{C}$ water temperature gave the lowest results of mortality rate for all period of rearing and level of hormone with significant differences. These results are relatively in agreement with those obtained by Baras $\boldsymbol{e t}$ al. (2001) and Bezault et al. (2007).

Concerning the effect of period of rearing on the mortality rate of Nile tilapia, the results indicate that the mortality rate of Nile tilapia increases with increasing period of rearing. Since the average values of the mortality rate were $13.29,14.63,15.30$ and $15.74 \%$ for Nile tilapia fries rearing at 1,2, 3 and 4 weeks of rearing period, respectively depending on the water temperature and hormone level. The highest value of the mortality rate of Nile tilapia (15.74\%) obtained at period of 4 weeks.

The results also indicate that the mortality rate of Nile tilapia ranged from 14.10 and $15.38 \%$ for 0 and $60 \mathrm{mg} 17 \alpha-\mathrm{MT} / \mathrm{kg}$ feed, respectively. 
The statistical analysis showed that the differences between the obtained data of male ratio of Nile tilapia due to the effect of water temperature (A), time period (B) and level of hormone (C) were significant. The analysis showed also that the interaction between $\mathrm{AB}, \mathrm{AC}$ and $\mathrm{BC}$ was significant. On the other hand, the interaction between the effects of both $\mathrm{ABC}$ on the data was non-significant.

Table (2): Effect of water temperature, time period and level of hormone on mortality of Nile tilapia.

\begin{tabular}{|c|c|c|c|c|c|c|c|}
\hline \multirow{3}{*}{$\begin{array}{c}\text { Hormone } \\
\text { Dose, } \mathrm{mg} \mathrm{kg}^{-1}\end{array}$} & \multirow{3}{*}{$\begin{array}{c}\text { Water } \\
\text { Temperature, }{ }^{\circ} \mathrm{C}\end{array}$} & \multicolumn{5}{|c|}{ Time Period, week } & \multirow{3}{*}{ Mean } \\
\hline & & 1 & 2 & 3 & \multirow{2}{*}{\multicolumn{2}{|c|}{4}} & \\
\hline & & \multicolumn{3}{|c|}{ Mortality Rate, \% } & & & \\
\hline \multirow{4}{*}{0} & 25 & 10.26 & 11.25 & 12.00 & \multicolumn{2}{|c|}{12.21} & $11.43^{a}$ \\
\hline & 30 & 14.09 & 14.09 & 16.14 & \multicolumn{2}{|c|}{16.71} & $15.26^{c}$ \\
\hline & 35 & 14.27 & 15.74 & 16.01 & \multicolumn{2}{|c|}{16.43} & $15.61^{c}$ \\
\hline & Mean & $12.87^{a}$ & $13.69^{b}$ & $14.72^{c}$ & \multicolumn{2}{|c|}{$15.12^{d}$} & \\
\hline \multirow{4}{*}{60} & 25 & 11.17 & 12.79 & 13.23 & \multicolumn{2}{|c|}{13.70} & $12.72^{b}$ \\
\hline & 30 & 14.77 & 16.81 & 17.10 & \multicolumn{2}{|c|}{17.56} & $16.56^{d}$ \\
\hline & 35 & 15.16 & 17.09 & 17.31 & \multicolumn{2}{|c|}{17.84} & $16.85^{\mathrm{e}}$ \\
\hline & Mean & $1^{13.70^{b}}$ & $15.56^{\mathrm{e}}$ & $15.88^{\text {ef }}$ & \multicolumn{2}{|c|}{$16.37^{\mathrm{g}}$} & \\
\hline \multirow{2}{*}{$\mathrm{LSD}_{0.05}$} & $\mathrm{~A}$ & $\mathrm{~B}$ & $\mathrm{C}$ & $\mathrm{AB}$ & $\mathrm{AC}$ & $\mathrm{BC}$ & $\mathrm{ABC}$ \\
\hline & 0.115 & 0.141 & 0.199 & 0.163 & 0.230 & 0.282 & N.S \\
\hline
\end{tabular}

\section{Weight gain of Nile tilapia fry:}

Table (3) shows the weight gain of Nile tilapia under two levels of hormone dose ( 0 and $60 \mathrm{mg} 17 \alpha-\mathrm{MT} / \mathrm{kg}$ feed) as affected by water temperatures from 25 to $35{ }^{\circ} \mathrm{C}$ and time periods from 1 to 4 weeks. Regarding of the effect water temperature, it could be seen that the average values of the weight gain of Nile tilapia fry were $0.78,1.28$ and $0.78 \mathrm{~g}$ for Nile tilapia fry rearing at 25,30 and $35{ }^{\circ} \mathrm{C}$ water temperature, respectively depending on the period and hormone level. The highest value of the male ratio of Nile tilapia $(1.28 \mathrm{~g})$ was obtained at water temperature of $30{ }^{\circ} \mathrm{C}$. The results revealed that the weight gain of Nile tilapia increased with increasing the water temperature from 25 to $30{ }^{\circ} \mathrm{C}$. These results almost agreed with those obtained by Khater (2012) who mentioned that the optimum required temperature of Nile tilapia fish growth $\left(28 \pm 2{ }^{\circ} \mathrm{C}\right)$. 
Table (3): Effect of water temperature, period and level of hormone on weight gain of Nile tilapia.

\begin{tabular}{|c|c|c|c|c|c|c|c|}
\hline \multirow{3}{*}{$\begin{array}{c}\text { Hormone } \\
\text { Dose, } \mathrm{mg} \mathrm{kg}^{-1}\end{array}$} & \multirow{3}{*}{$\begin{array}{c}\text { Water } \\
\text { Temperature, }{ }^{\circ} \mathrm{C}\end{array}$} & \multicolumn{5}{|c|}{ Time Period, week } & \\
\hline & & 1 & 2 & 3 & & 4 & \\
\hline & & \multicolumn{5}{|c|}{ Weight gain, $g$} & \multirow{2}{*}{$\begin{array}{c}\text { Mean } \\
0.75\end{array}$} \\
\hline \multirow{4}{*}{0} & 25 & 0.10 & 0.35 & 0.93 & & 1.63 & \\
\hline & 30 & 0.26 & 0.51 & 1.78 & & 2.40 & 1.24 \\
\hline & 35 & 0.21 & 0.32 & 0.92 & & 1.59 & 0.76 \\
\hline & Mean & 0.19 & 0.39 & 1.21 & & 1.87 & \\
\hline \multirow{4}{*}{60} & 25 & 0.19 & 0.39 & 1.01 & & 1.66 & 0.81 \\
\hline & 30 & 0.28 & 0.55 & 1.86 & & 2.56 & 1.31 \\
\hline & 35 & 0.26 & 0.38 & 0.96 & & 1.61 & 0.81 \\
\hline & Mean & 0.24 & 0.44 & 1.28 & & 1.94 & \\
\hline \multirow{2}{*}{$\mathrm{LSD}_{0.05}$} & A & B & $\mathrm{C}$ & $\mathrm{AB}$ & $\mathrm{AC}$ & $\mathrm{BC}$ & $\mathrm{ABC}$ \\
\hline & 0.008 & 0.010 & 0.012 & N.S & N.S & 0.020 & N.S \\
\hline
\end{tabular}

Concerning the effect of period of rearing on the weight gain of Nile tilapia, the results indicate that the weight gain of Nile tilapia increases with increasing period of rearing. It is significantly increased from 0.22 to $1.91 \mathrm{~g}$, when the rearing period increasing from 1 to 4 weeks depending on the water temperature and hormone level. The results also showed that the weight gain of Nile tilapia increased from 0.92 and 0.98 $\mathrm{g}$ for 0 and $60 \mathrm{mg} 17 \alpha-\mathrm{MT} / \mathrm{kg}$ feed, respectively. The statistical analysis showed that the differences between the obtained data of male ratio of Nile tilapia due to the effect of water temperature (A), time period (B) and level of hormone $(\mathrm{C})$ were significant. The analysis showed also that the interaction between both $\mathrm{BC}$ were significant. On the other hand, the interaction between the effect of $\mathrm{AB}, \mathrm{AC}$ and $\mathrm{ABC}$ on the data was nonsignificant.

\subsection{Energy Consumption for heating water:}

Figure (2) shows the energy consumption for heating water to maintain of water temperature at 25,30 and $35^{\circ} \mathrm{C}$ at different periods $(1,2,3$ and 4 weeks). The results indicated that the energy consumption for heating water increases with increasing water temperature and rearing period. Since, as the water temperature increased from 25 to $35^{\circ} \mathrm{C}$, the energy consumption increased from 270.00 to $326.67,533.33$ to $640.00,820.00$ to 990.00 and 1246.67 to $1286.67 \mathrm{~kW} / 100000$ fry after $1,2,3$ and 4 weeks, respectively. 
The results also indicate that the highest value of energy consumption for water heating (1286.67 kW/100000 fry) found at $35{ }^{\circ} \mathrm{C}$ water temperature after four weeks of period rearing. While the lowest value of energy consumption for water heating $(270.00 \mathrm{~kW} / 100000$ fry) found at $25^{\circ} \mathrm{C}$ water temperature after one week of period rearing.

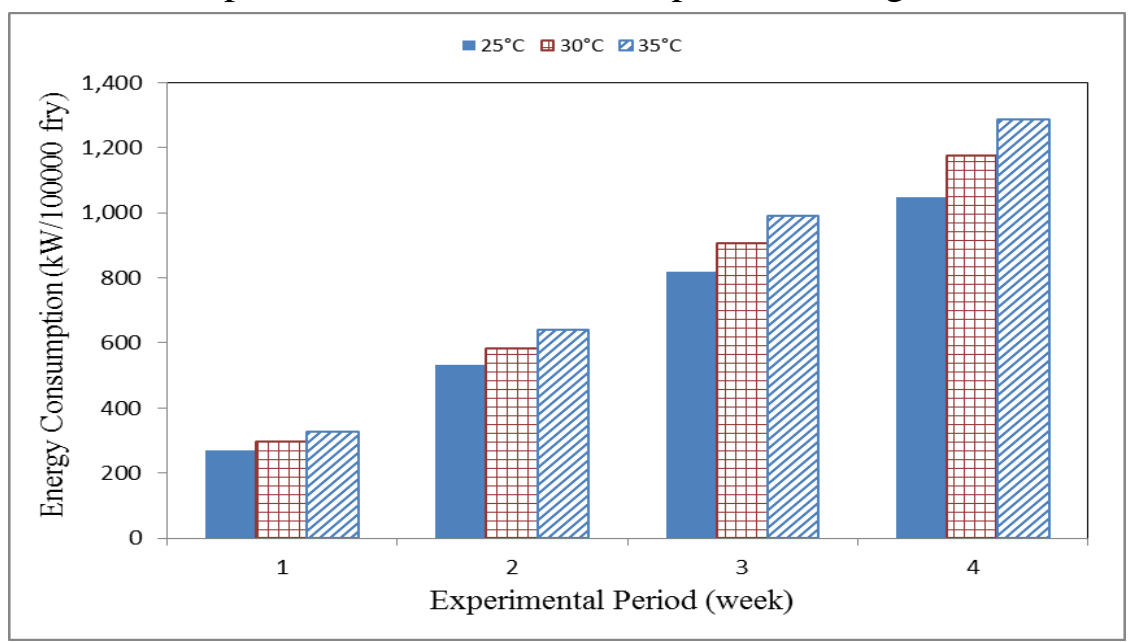

Figure (2): The energy consumption for heating water at different water temperature and different time of periods.

Multiple regression analysis was carried out to find a relation between the energy consumption for heating water and both water temperatures and periods of rearing. Equation (18) shows the most appropriate form for the relationship between the energy consumption for heating water and both water temperatures $\left(25-35^{\circ} \mathrm{C}\right)$ and periods of rearing $(1-4$ week).

$$
E C=-423.893+14.334 W T+293.222 T P \quad \mathrm{R}^{2}=0.99
$$

Where:

$\mathrm{EC}$ is the energy consumption for heating water, $\mathrm{kW} / 100000$ fry

WT is the water temperature, ${ }^{\circ} \mathrm{C}$

TP is the time of period, week

\section{Costs of heating water and hormone:}

Table (4) shows the costs of heating water and hormone under two levels of hormone dose ( 0 and $60 \mathrm{mg} 17 \alpha-\mathrm{MT} / \mathrm{kg}$ feed $)$ as affected by water temperatures from 25 to $35^{\circ} \mathrm{C}$ and time periods from 1 to 4 weeks. The results indicated that the costs of heating water and hormone increases 
with increasing hormone dose, water temperature and rearing period. It could be seen that, when the water temperature increased from 25 to 35 ${ }^{\circ} \mathrm{C}$, the costs increased from 180.90 to $218.87,357.33$ to $428.80,549.40$ to 663.30 and 701.27 to 862.07 L.E/100000 fry after 1, 2, 3 and 4 weeks, respectively at 0 hormone level. At $60 \mathrm{mg} 17 \alpha-\mathrm{MT} / \mathrm{kg}$ feed, the costs increased from 186.73 to $226.59,368.58$ to $439.78,577.46$ to 690.00 and 746.94 to 906.39 L.E/100000 fry after 1, 2, 3 and 4 weeks, respectively.

The results also indicate that the highest value of cost (906.39 L.E/100000 fry) was found at $35^{\circ} \mathrm{C}$ water temperature with $60 \mathrm{mg} 17 \alpha$ $\mathrm{MT} / \mathrm{kg}$ feed after four weeks of period rearing. While the lowest value of cost (180.90 L.E/100000 fry) was found at $25{ }^{\circ} \mathrm{C}$ water temperature with 0 -hormone level after one week of period rearing.

Table (4): Effect of water temperature, period and level of hormone on costs production of Nile tilapia fry.

\begin{tabular}{|c|c|c|c|c|c|}
\hline \multirow{3}{*}{$\begin{array}{c}\text { Hormone } \\
\text { Dose, } \mathrm{mg} \mathrm{kg}^{-1}\end{array}$} & \multirow{2}{*}{$\begin{array}{c}\text { Temperater } \\
\text { Tere, }\end{array}$} & \multicolumn{4}{|c|}{ Time Period, week } \\
\cline { 3 - 6 } & & 1 & \multicolumn{4}{|c|}{ Cost, L.E per 100000 fry } \\
\hline \multirow{3}{*}{0} & 25 & 180.90 & 357.33 & 549.40 & 701.27 \\
\cline { 2 - 6 } & 30 & 198.77 & 390.83 & 605.23 & 786.13 \\
\cline { 2 - 6 } & 35 & 218.87 & 428.80 & 663.30 & 862.07 \\
\hline \multirow{4}{*}{60} & 25 & 186.73 & 368.58 & 577.46 & 746.94 \\
\cline { 2 - 6 } & 30 & 207.03 & 406.42 & 656.33 & 856.21 \\
\cline { 2 - 6 } & 35 & 226.59 & 439.78 & 690.00 & 906.39 \\
\hline
\end{tabular}

Price of hormone $=3 \mathrm{~L} . \mathrm{E} \mathrm{g}^{-1} \quad$ Price of energy $=0.67 \mathrm{~L} . \mathrm{E} \mathrm{kW}^{-1}$

The results also indicate that the water temperature of $35^{\circ} \mathrm{C}$ with $60 \mathrm{mg}$ $17 \alpha-\mathrm{MT} / \mathrm{kg}$ feed after two weeks gave the best results of male ratio and costs compared to water temperature of $35^{\circ} \mathrm{C}$ with 0 hormone doses after four weeks. Where, the male ratio and cost production were $94.86 \%$ and 439.48 L.E $/ 100000$ fry, respectively, at $35^{\circ} \mathrm{C}$ water temperature with 60 mg $17 \alpha-\mathrm{MT} / \mathrm{kg}$ feed after two weeks, while they were $90.65 \%$ and 862.07 L.E/ 100000 fry, respectively, at $35^{\circ} \mathrm{C}$ water temperature with 0 hormone doses after four weeks. The cost production of Nile tilapia fry at $35^{\circ} \mathrm{C}$ water temperature with 0 hormone doses after four weeks was twice as high as those at $35^{\circ} \mathrm{C}$ water temperature with $60 \mathrm{mg} 17 \alpha-\mathrm{MT} /$ $\mathrm{kg}$ feed after two weeks. 
The results also indicate that the water temperature of $35^{\circ} \mathrm{C}$ with $60 \mathrm{mg}$ $17 \alpha-\mathrm{MT} / \mathrm{kg}$ feed after one week gave the best results of male ratio and costs compared to water temperature of $35^{\circ} \mathrm{C}$ with 0 hormone doses after three weeks. Where, the male ratio and cost production were $86.95 \%$ and $226.59 \mathrm{~L} . \mathrm{E} / 100000$ fry, respectively, at $35^{\circ} \mathrm{C}$ water temperature with 60 mg $17 \alpha-\mathrm{MT} / \mathrm{kg}$ feed after one week, while they were $87.78 \%$ and 663.30 L.E/ 100000 fry, respectively, at $35^{\circ} \mathrm{C}$ water temperature with 0 hormone doses after three weeks. The cost production of Nile tilapia fry at $35^{\circ} \mathrm{C}$ water temperature with 0 hormone doses after three weeks was three times as high as those at $35^{\circ} \mathrm{C}$ water temperature with $60 \mathrm{mg} 17 \alpha$ $\mathrm{MT} / \mathrm{kg}$ feed after one week.

\section{CONCLUSIONS}

\section{The obtained results can summarized as follows:}

1-The highest value of male ratio $(98.98 \%)$ was obtained at $35{ }^{\circ} \mathrm{C}$ water temperature with $60 \mathrm{mg} 17 \alpha-\mathrm{MT} / \mathrm{kg}$ feed after four week of rearing.

2-Otherwise, the mortality rate was significantly the highest $(16.23 \%)$ at $35{ }^{\circ} \mathrm{C}$ depending on the period of treatment and hormone level. Similarly, it was the highest also with $60 \mathrm{mg} 17 \alpha-\mathrm{MT} / \mathrm{kg}$ feed (15.38 $\%)$.

3-The highest value of weight gain $(2.56 \mathrm{~g})$ was obtained at $30{ }^{\circ} \mathrm{C}$ water temperature with $60 \mathrm{mg} 17 \alpha-\mathrm{MT} / \mathrm{kg}$ feed after four week of rearing.

4-The energy consumption for heating water increased from 270.00 to $326.67,533.33$ to $640.00,820.00$ to 990.00 and 1246.67 to 1286.67 $\mathrm{kW} / 100000$ fry, when the water temperature increased from 25 to $35^{\circ} \mathrm{C}$, after 1, 2, 3 and 4 weeks, respectively.

5-The water temperature of $35^{\circ} \mathrm{C}$ with $60 \mathrm{mg} 17 \alpha-\mathrm{MT} / \mathrm{kg}$ feed after two weeks gave the best results of male ratio and costs compared to water temperature of $35^{\circ} \mathrm{C}$ with 0 hormone doses after four weeks. In addition, the water temperature of $35^{\circ} \mathrm{C}$ with $60 \mathrm{mg} 17 \alpha-\mathrm{MT} / \mathrm{kg}$ feed after one week gave the best results of male ratio and costs compared to water temperature of $35^{\circ} \mathrm{C}$ with 0 hormone doses after three weeks.

\section{REFERENCES}

Anonymous, (1992). ASAE Standards, 1992, 39th edition. American Society of Agricultural Engineers. St. Joseph, MI. 781 pp. 
Baras, E., B. Jacobs and C. Melard (2001). Effect of water temperature on survival, growth and phenotypic sex of mixed (XX-XY) progenies of Nile tilapia Oreochromis niloticus. Aquaculture, 192: 187-199.

Baroiller, J. F., A. Fostier, C. Cauty, X. Rognon and B. Jalabert (1996). Effects of high rearing temperatures on sex ratio of progeny from sex reversed males of Oreochromis niloticus. In: Pullin, R.S.V., Lazard, J., Legendre, M., Amon Kothias, J.B., Pauly, D. (Eds.). The Third International Symposium on Tilapia in Aquaculture. ICLARM Conference Proceedings, 41: 246-256.

Bezault, E., F. Clota, M. Derivaz, B. Chevassus and J. Baroiller (2007). Sex determination and temperature-induced sex differentiation in three natural populations of Nile tilapia (Oreochromis niloticus) adapted to extreme temperature conditions. Aquaculture 272, 3-16.

Bliss, R. W. (1961). Atmospheric Radiation near the Surface of the Ground. Solar Energy 5:103-120.

Cathcart, T. P. (1987). Heat transfer and temperature prediction in small freshwater ponds. Ph.D. dissertation, Department of Agricultural Engineering, University of Maryland, 283 PP.

Celik, I., Y. Guner and P. Celik (2011). Effect of orally - administered $17 \alpha$-methyltestosterone at different doses on the sex reversal of the Nile tilapia (Oreochromis niloticus, L. 1758). J. Anim. Vet. Adv., 10 (7): 853-857.

Devlin, R. H., and Y. Nagahama (2002). Sex determination and sex differentiation in fish: an overview of genetic, physiological, and environmental influences. Aquaculture, 208: 191-364.

Gomez, K. A. (1984). Statistical Procedures for Agricultural Research, 2nd ed. John Wiely\& Sons, New York, USA 680 pp.

Guerrero III, R. D. and L. A. Guerreiro (1997). Effects of Androstenedione and methyltestosterone on Oreochromis niloticus fry treated for sex reversal in outdoor net enclosure. In: International Symposium on Tilapia in Aquaculture, 4, 1997, Orlando, Florida. Proceedings. Orlando, 12: 772-777.

Guerrero, R. D. and W. L. Shelton (1974). An aceto-carmine squash method for sexing juvenile fishes. Prog. Fish-Cult., 36:56.

Holman, J. P. (1997). Heat Transfer, 8th edition. McGraw-Hill. 696 pp. 
Jauncey, K. and B. Ross (1982). A guide to tilapia feeds and feeding. Institute of aquaculture, university of sterling, Scotland. $111 \mathrm{pp}$.

Khater, A. M. (1999). Sex reversal in tilapia nilotica. Ph. D., Thesis, Fac. Agric., Zagaaig Univ., Egypt.

Khater, E.G. (2012). Simulation model for design and management of water recirculating systems in aquaculture. Ph. D., Thesis, Fac. Agric., Moshtohor, Benha Univ., Egypt.

Khater, E.G., S.A. Ali and W. E. Mohamed (2017). Effect of water temperature on masculinization and growth of Nile tilapia fish. J. Aquac. Res. Development, 8: 507. doi: 10.4172/2155-9546.1000507

Killian, H.S. and C.C. Kohler (1991). Influence of $17 \alpha$ methyltestosterone one on Red tilapia under two thermal regime. J. World Aquac. Soc. 22 (2), 83-94.

Macintosh, D.J. and D. C. Little (1995). Nile tilapia (Oreochromis niloticus). In: Bromage, N.R. and Roberts, R.J. (Eds.). Broodstock management and egg and larval quality. Cambridge: Blackwell, pp. 277-320.

Meadmore, J. A., G. C. Mairal and R. I. Lewisb (2001). Monosex male production in finfish as exemplified by tilapia: applications, problems, and prospects. Aquaculture, 197: 283-301.

Mubarik, M. S., I. Ahmed, A. Mateen and T. Iqbal (2011). 17 $\alpha$ Methyltestosterone induced masculinization and its effect on growth and meat quality of Cyprinus carpio. Int. J. Agric. Biol., 13(6): 971975.

Piedrahita, R.H. (1991). Modeling water quality in aquaculture ecosystem. In: D. E. Brune and J. R. Tomasso (Editors). Aquaculture and Water Quality. World Aquaculture Society. Baton Rouge, LA, pp. $322-362$.

Popma, T. J. and R. P. Phelps (1998). Status report to commercial tilapia producers on monosex fingerling productions techniques. In: Aquacltura Brasil 98, 1998, Recife. Anais. Recife: SIMBRAQ, pp. 127-145.

Rakocy, J. E. (1989). Tank culture of tilapia. In the biology and culture of tilapia, ed. R. S. V. Pullin \& R. H. Lowe-McConell-ICLARM conference proceedings 7 . International center for living aquatic resources management, manila, the Philippines. 
Shelton, W. L., V. Wanniasingham and A. E. Hiott (1995). Ovarian differentiation in common carp (Cyprinus carpio) in relation to growth rate. Aquaculture, 137: 203-211.

Snedecor, G. W. and W. G. Cochran (1980). Statistical Methods, $7^{\text {th }}$ Ed., Iowa State University Press, Ames, Iowa, USA.

Soto-Zarazúa M. G., E. Rico-García and M. Toledano-Ayala (2011). Temperature effect on fish culture tank facilities inside greenhouse. Int. J. Phys. Sci., 6(5): 1039-1044.

Tessema, M., A. Müller-Belecke and G. Hörstgen-Schwark (2006). Effect of rearing temperatures on the sex ratios of Oreochromis niloticus populations. Aquaculture, 258: 270-277.

Tsadik, G. G. and A. N. Bart (2007). Effect of feeding stocking density and water-flow rate on fecundity, spawning frequency and egg quality of Nile tilapia, Oreochromis niloticus (L.). Aquaculture, 272: 380388.

Wessels, S. and G. Hörstgen-Schwark (2007). Selection experiments to increase the proportion of males in Nile Tilapia (Oreochromis niloticus) by means of temperature treatment. Aquaculture, 271: 8087.

Wessels, S. and G. Hörstgen-Schwark (2011). Temperature dependent sex ratios in selected lines and crosses with a YY-male in Nile tilapia (Oreochromis niloticus). Aquaculture, 318: 79-84. 


\section{دراسة فنية مالية لبعض طرق التحول الجنسى لاسماك البلطى التيلى 'البى

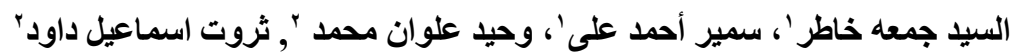

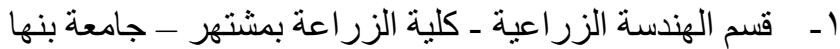

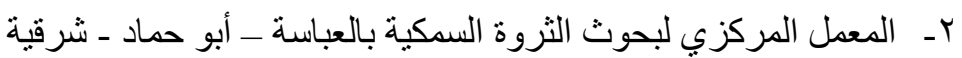

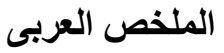

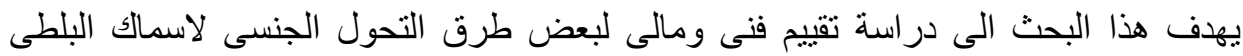

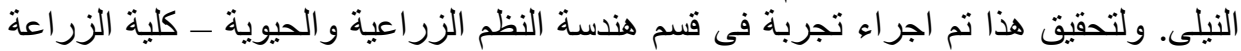

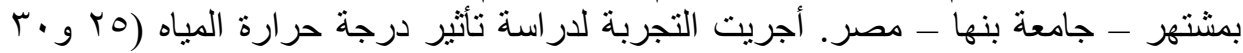

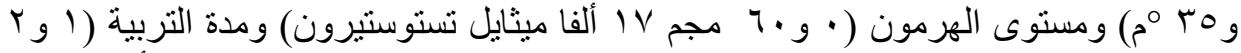

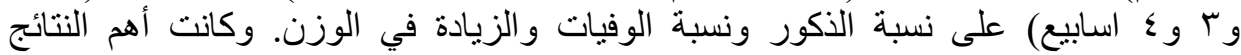

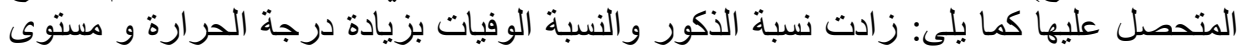

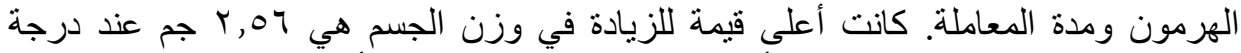

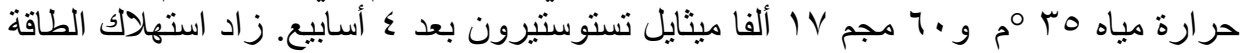

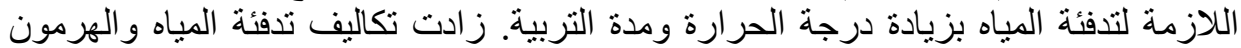

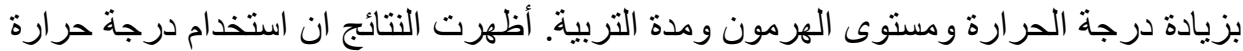

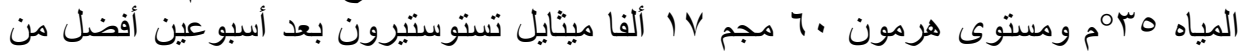

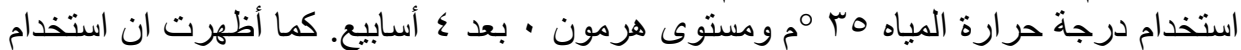

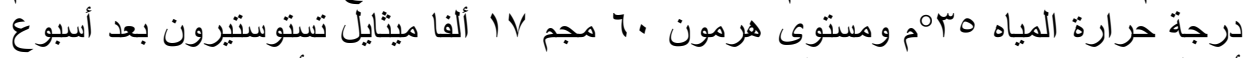

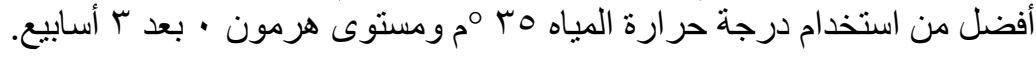

